\title{
Professional Expectations and Program Climate Affect the Professional For- mation of Engineers
}

\section{Dr. Manuel Alejandro Figueroa, The College of New Jersey}

Dr. Manuel Figueroa is an Assistant Professor in the School of Engineering at The College of New Jersey. He teaches in the Department of Integrative STEM Education and prepares pre-service teachers to become $\mathrm{K}-12$ technology and engineering educators. His research involves engaging college students in human centered design and improving creativity. He also develops biotechnology and nanotechnology inspired lessons that naturally integrate the STEM disciplines. He received his $\mathrm{PhD}$ in biomedical engineering from Drexel University and was an NSF Graduate STEM Fellow in K-12 Education (GK-12).

\section{Dr. Diane C. Bates, The College of New Jersey}

Dr. Diane C. Bates is a Professor of Sociology, with research interest and expertise in education in quantitative methods and retention in higher education in STEM disciplines.

\section{J. Lynn Gazley, The College of New Jersey}

J. Lynn Gazley is Associate Professor of Sociology at TCNJ. Her research interests focus on diversity and inclusion in the sciences, and how these processes shape scientific knowledge-making. She has served as a Research Associate and Visiting Scholar with Northwestern University's Scientific Careers Research and Development Group since 2010, working on a longitudinal study of over 200 graduate students in the life sciences.Her major research project, the National Science Foundation (NSF)-funded "FIRSTS (Foundation for Increasing and Retaining STEM Students) Program: A Bridge Program to Study the Development of Science Identities," examines mentoring relationships, identity development, and the role of outside-of-college commitments in persistence among students coming to STEM majors with limited financial support.

\section{Dr. Christopher Wagner, The College of New Jersey}

Dr. Wagner is currently Associate Professor of Biomedical Engineering (BME) at The College of New Jersey (TCNJ), where he has taught students at all levels of the curriculum. For over 14 years prior to joining TCNJ, he was engaged in medical device technology and product development for the Biosurgery and Regenerative Medicine markets. He coordinates the BME Capstone Senior Project course, wherein students design and prototype novel medical devices within the Design Control framework, preparing them for development careers in the medical device industry. He earned a BS degree in Chemical Engineering with Certificates in Biomedical Engineering and Personnel Management from the University of Rochester, followed by a Doctorate in Chemical Engineering from Rice University for research investigating fluid dynamic shear force effects on platelet activation and genetic regulation of vascular smooth muscle cells. His current research interests focus on mechanical stimulation effects on cellular differentiation, natural tissues as bioscaffolds, and tissue engineering mechanically sensitive tissues.

\section{Dr. Steven Schreiner P.E., The College of New Jersey}

Prof. Bijan Sepahpour P.E., The College of New Jersey

Bijan Sepahpour is a registered Professional Engineer and a Professor of Mechanical Engineering at the College of New Jersey (TCNJ). He has served as the Chairperson of the ME department at TCNJ from 2006 through 2015. Prof. Sepahpour has been actively involved in the generation of design-oriented exercises and development of laboratory apparatus and experiments in the areas of mechanics of materials and dynamics of machinery for undergraduate engineering programs. He has advised on over forty (40) Senior Design Projects and his teams of students have received five (5) National Championships and three Best Design Awards. In the recent years, he has challenged himself with the creation of an effective methodology for successful Invention and Innovation. He was part of a 14 member multi-disciplinary team to design and create the "Society, Ethics, and Technology (SET)" course at TCNJ in 1994 and has 
taught multiple regular and Honors sections of this course since then. He is currently leading a multidisciplinary team of faculty from TCNJ's School of Engineering and the Department of Sociology for assessment of the Professional Formation of Engineers (PFE). Professor Sepahpour did his undergraduate studies at TCNJ and has advanced degrees from New Jersey Institute of Technology (NJIT). He is the recipient of two (2) Best Paper Awards from the American Society for Engineering Education (ASEE) Divisions of Mechanical Engineering (ME) and Experimentation and Laboratory Oriented Studies (DELOS). He has served as the Chair of the Divisions of ME and DELOS of the ASEE. Prof. Sepahpour is an active member of American Society of Mechanical Engineers (ASME) and ASEE and has published and presented extensively through these societies. 


\title{
Professional Expectations and Program Climate affects the Professional Formation of Engineers
}

\begin{abstract}
This research paper explores how engineering undergraduates change their understanding of professional expectations from the first year to near graduation, and whether that understanding varies across gender, race, and/or ethnicity of students. We investigate these questions by analyzing semi-structured, qualitative interview transcripts from 37 engineering undergraduates, who were either in their first semester of their first year or in the second semester of their junior year. Students were selected purposively, with over samples of women and black/African American and Hispanic students.
\end{abstract}

In their first semester, students emphasized an academic and pre-professional culture that principally values academic performance, which they viewed mostly as a sink-or-swim, weeding out process. Advanced students, in contrast, emphasized the importance of skills such as teamwork and collegiality over grades for professional formation. Students explain both academic performance and the development of other professional skills as fundamentally meritocratic: underrepresentation of women and some racial and ethnic groups in engineering majors and in the engineering profession were viewed as personal choice or inability to do the necessary work. These narratives are widespread among students, despite the different preparation levels among first year students and the fact that many women and students of color report first and second hand discriminatory experiences before they graduate. We thus suggest that a "color-blind" and gender-blind undergraduate professional culture is constructed by students to obfuscate inhospitable climates and persistent structural challenges for women and students of color.

\section{INTRODUCTION:}

Recent national reports show the United States does not produce enough engineering students to stay globally competitive with other countries [1, 2]. Furthermore, employers consistently express their need to hire a more diverse workforce as well as students who exhibit professional engineering competencies in communication, systems thinking, design, teamwork, and project planning [3]. The traditional emphasis on developing students with theoretical and analytical skills, and the heavy load of engineering science and mathematics courses during the first two years of college leads many students to concentrate more on academic performance and not realize the importance of developing professional skills. 
Over the past 30 years, there have been notable curriculum shifts in engineering education to meet the needs of industry and the standards of ABET Accreditation. According to general criterion \#5, "students are prepared to enter the practice of engineering through a curriculum that includes a culminating major design experience" [4]. Almost all engineering programs now have a senior design capstone course and upper level professional courses which prepare students to transition into the workforce [5-7]. Many programs also offer professional seminars into the course sequence [8] as well as cornerstone design courses which can improve integration into their disciplines and social integration with their peers [9]. These type of courses have many positive effects including exposing students earlier to "real-world" design experiences, discussing the ethical responsibilities of the profession, cultivating engineering habits of mind, meeting their future professors, and forming friendships with their fellow classmates. The formal experiences offered in these courses can help students develop a strong identification with engineering [10].

Historically, attrition in engineering programs is greater for women and students from underrepresented racial and ethnic groups when compared to white males. There is some evidence that the implementation of design courses and hands on learning can increase retention of women and students of color [11, 12]. According to an NSF 2017 report on degrees earned in the science and engineering fields, the percentage of white women earning a bachelor's degree in engineering modestly increased from 17.3\% to 19.8\% from 1995 to 2014. During the same time period, the percentage of African American engineering graduates decreased from $4.49 \%$ to $3.83 \%$ while Hispanics engineering graduates increased from $5.76 \%$ to $9.56 \%[13]$.

Beyond formal experiences within the program, the formation of a professional identity is just as much shaped by the informal experiences in the program $[3,10]$. These can include the ability to seek an internship or research experience, the prevailing culture in the department, involvement in professional student organizations, program support, solidarity between students, etc. Positive environmental factors at the departmental and institutional level can enhance a student's feeling of belonging and encourage their persistence in the program [14].

The combination of formal and informal experiences contribute to the overall climate of the program. Students who feel comfortable and accepted in their academic program have lower rates of attrition [15]. In a previous paper, we developed a new survey index to characterize engineering climate based on social integration, faculty support, sense of community, and equitable opportunities [16]. In addition, we found that students' perception of whether there is equal treatment and sensitivity to inequality better predicts professional formation than their individual demographic factors such as race, gender, sexual orientation and class. 
In this study, we continue the work on understanding program climate through a qualitative analysis of interview transcripts from first year and junior/senior students. We make an effort to understand how students perceive the climate as they navigate through their engineering program and how it influences their formation of professional identity. We did not analyze precollege experiences, family influences or personalities. We acknowledge these factors have been shown to be strong predictors of professional integration into the engineering major, particularly for students of color [15] but they are outside of the scope of this paper.

We analyzed transcribed interviews from engineering students at the end of their first semester and at the end of their junior year to try to answer the following research questions:

1. How does the engineering climate in a small liberal arts institution influence student's formation of a professional engineering identity?

2. How is the engineering climate perceived differently by women and men?

3. What observations can we make about students of color on their perceptions of engineering climate and their professional identity formation?

\section{Conceptual Framework}

Robust engineering identities, like other STEM identities, are associated with persistence via multiple pathways, including self-efficacy and motivation [17, 18]. These identities must balance individual affiliation with three aspects of a field: doing (hands on practices), being (habits of mind), and becoming (professional aspirations) [19]. Individuals construct these identities over time via interaction with material and social contexts [20,21]. As individuals gain experience over time, particularly in real-world vs. classroom settings, these aspects may develop at different rates. Thus, to understand the professional formation of the novice engineers in our study, we must identify the interaction between factors within a program's culture pertaining to who and how one can succeed and the students' internalization of their own competencies within that context [21].

Although race and gender have been shown to shape engineering persistence and professionalization in multiple ways, individuals commonly explain differential achievement as a function of meritocracy rather than of system-based discrimination, even as a way to frame their own experiences [22]. Within educational settings, the interplay between social identities and academic excellence plays out in complicated ways. For example, although women often outperform their male colleagues in the classroom, Seron and colleagues (2017) find professional socialization practices, particularly those pertaining to informal learning experiences, can re-inscribe professional sex segregation by relegating women to traditional 
gendered roles and expressions [23]. Where men experience increasing role fit which supports their developing confidence, women's assignment to supporting roles in internships and on project teams dissociates them from their original professional aspirations and may lead them to question their fit with engineering.

\section{METHODS:}

Because this study is designed to explore the subjective experiences of undergraduate engineering students in depth, we conducted face-to-face semi-structured interviews. Interviews were conducted on campus, were electronically recorded, and professionally transcribed. The authors reviewed and coded each transcript, with at least two authors reviewing each transcript.

The School of Engineering is situated in a primarily undergraduate, liberal arts-focused, selective public institution enrolling about 6,500 students. Engineering students acquire a foundation in the humanities and social sciences and develop an understanding of societal issues, as well as critical thinking, metacognition, and communication skills through the liberal arts core program. In the Fall 2016 semester, about 600 undergraduates were enrolled in engineering majors, of which approximately one quarter are women and one fifth are members of historically underrepresented racial or ethnic groups. Official enrollment data indicated that the School of Engineering students were $68 \%$ non-Hispanic white and $76 \%$ male.

The samples for this study were drawn from the population of first-year students in Fall 2016 and juniors and seniors in 2017, purposively oversampling women and historically underrepresented groups. Our final sample includes 38 individuals in 37 interviews, of which $50 \%$ were female $(n=19)$ and at least $60 \%$ were non-Hispanic whites $(n=23$; three respondents declined to give race/ethnicity). Despite our attempts to oversample by race/ethnicity and gender, we were unable to interview any African American women. The distribution of respondents by race/ethnicity and gender can be seen in Table 1.

The sample of first-year engineering students was selected using a reputational method: the faculty member teaching the first-year non-credit seminar for engineering students and the dean of engineering were asked to identify four or five students who would be effective informants in four categories (white/Asian men, white/Asian women, black/Latino men, black/Latina women). The intent of involving the dean was to increase participation not to create a non-representational sample. This produced a pool of 16 first-year students; of these, 11 interviews were done with first year students (response rate $=69.75 \%$ ). Just under half of first-year respondents were men $(n=5)$ and half were white, non-Hispanic $(n=5)$. Although we 
Table 1: Interview transcripts analyzed by race \& ethnicity and gender ( +1 refers to an interview with 2 students).

\begin{tabular}{|c|c|c|c|}
\hline Race \& Ethnicity & Male & Female & Total \\
\hline White, Non-Hispanic & 11 & 12 & 23 \\
\hline Black/African American & 2 & 0 & 2 \\
\hline Hispanic/Latinx & 2 & 2 & 4 \\
\hline $\begin{array}{c}\text { Asian American/ } \\
\text { Pacific Islander }\end{array}$ & 3 & 2 & 5 \\
\hline No Data & 1 & $2(+1)$ & $3(+1)$ \\
\hline Total & 19 & $18(+1)$ & $37(+1)$ \\
\hline
\end{tabular}

make no claims that this is a representative sample, at this point, the authors conducting interviews determined that a saturation point was reached and no additional interviews were scheduled.

For interviews with juniors and seniors, respondents were selected in three waves. Initially, we pursued a reputational method similar to that used for first-year students: the dean of engineering and a faculty member teaching a senior seminar in engineering provided a list of 18 students distributed across four categories: white/Asian males, white/Asian females, black/Latino males, black/Latina females. Despite multiple attempts to secure interviews with these students, we were only able to conduct 4 interviews with junior and seniors, including one joint interview with two individuals. We then asked a racially and ethnically diverse group of 9 undergraduate research assistants to develop a list of 37 engineering juniors and seniors who would agree to be interviewed through social and academic networks. From these respondents, we purposely selected women and underrepresented minorities first and were able to complete 18 interviews (48.65\%). Students who were interviewed in this round were asked to name other potential engineering juniors and seniors who would agree to be interviewed (i.e., a snowball sample), and we were able to secure an additional four interviews, including one student who had completed coursework two months prior to being interviewed. After these interviews, the authors determined a saturation point was reached. The final sample of juniors and seniors, including the recent graduate, included 27 individuals in 26 interviews; of these slightly more than half of the respondents were men $(n=14)$ but most were non-Hispanic whites $(n=18)$. 
There are very few students of color in the sample but this is common in engineering programs at predominantly white institutions. Since aggregated survey results can hide problems in engineering environments, it is more appropriate to qualitatively analyze the transcripts from underrepresented students as has been discussed by others [24, 25].

Because we sampled students qualitatively, we do not expect our first-year and junior student samples to statistically represent the populations. Particularly among the first-year students, who were identified by faculty and the dean, students who are either strongly vested in the engineering program or attempting to "look good" to the program would be more likely to respond to our requests-- despite the fact that we clearly detailed how their identities would be kept confidential. Moreover, first-year students were all interviewed by faculty members, which may produce a sort of bias in responses in terms of students responding how they think faculty want them to respond. Thus, we expect that the first-year respondents may portray an optimistic or positive view of their experiences, and we expect that students who are already unhappy in their program would be less likely to agree to be interviewed. A different sort of bias is introduced in the junior snowball sample, with gatekeeping respondents identified through (non-engineering) undergraduate research assistants' social networks. Also, most junior interviews were conducted by peer interviewers, so they are less systematic and we lost many opportunities for follow-up questions. However, we found that the peer interviews were much more candid about sensitive issues, and were otherwise similar to the junior interviews conducted by faculty members and identified through a reputational sample.

Interviews were all recorded and transcribed, then deidentified. At this point, the authors reviewed the transcripts. After two authors reviewed all transcripts, a series of themes were proposed and an initial list of codes was developed by one of the authors, but which evolved with additional insight as additional people reviewed the transcripts. Each interview was reviewed and coded by at least two authors. The lead author eventually selected the quotes that most reflected the codes and themes that had developed iteratively by the team.

\section{Survey Data}

After completing interviews, we conducted pilot surveys to determine how widespread the patterns identified in the interviews were. Anonymous, online first-year and junior surveys were administered to all students registered in engineering programs via Qualtrics software.-These students who responded are not statistically representative of either class $(31.98 \%$ of first-year students and $44.0 \%$ of juniors, see Table 2), but samples were similar to the current School of Engineering undergraduate population in terms of race/ethnicity and sex. 
Table 2. Sample of first-year and junior surveys

\begin{tabular}{|c|c|c|c|}
\hline Category & $\begin{array}{c}\text { Number } \\
\text { surveyed }\end{array}$ & $\begin{array}{c}\text { Started survey } \\
\text { (response rate) }\end{array}$ & $\begin{array}{c}\text { Completed survey } \\
\text { (completion rate) }\end{array}$ \\
\hline First-year students & 172 & $58(33.72 \%)$ & $55(31.98 \%)$ \\
\hline Juniors & 125 & $63(46.4 \%)$ & $55(44.0 \%)$ \\
\hline
\end{tabular}

\section{RESULTS:}

The transcripts reveal first year students are overwhelmingly more focused on academic performance than developing professional skills. As is common to most engineering programs, the first two semesters are devoted to foundational courses in math and science [9]. In this program, students take physics, chemistry, calculus, computer science, a liberal learning elective, a first year humanities course, and an introductory design course. In addition, students take two non-credit bearing professional seminars that introduce the various majors as well as introduce discussion topics related to specific issues of their engineering disciplines. As they balance their course workload, students begin to conceptualize whether they belong within the engineering program. From the interview transcripts, there are two important formal experiences which first year students use as measures to determine if they belong in the program: 1) academic performance in courses and 2) their experience in professional seminars. This reflects ongoing work in the multiple dimensions of identity development, particularly in connecting academic competence ('can I do this', or academic self-efficacy) to professional aspirations ('do I belong', or professional role confidence).

\section{Course Performance - 'The Ultimatum'}

Course performance is the first measure freshman students use to determine how well they fit in the engineering program. This was true across majority groups and underrepresented students. However, many students who were well prepared and had strong family support commented that adjusting to college and learning how to study were the biggest obstacles they faced during their first year. Those students, who arrived to college with high school Advanced Placement course credits, described the content of the first semester as not much different than what they learned in high school. On the other hand female students and underrepresented students felt fear and anxiety over their academic performance. A first year (FY) Hispanic male student described the pressure students feel to perform well during the first year course sequence. 
I feel the ultimatum to absolutely pass your classes really scares [engineering majors] off of wanting to stay in engineering. There are a few people who didn't do well but didn't pass particular courses, like the requirement courses like physics and calculus... They failed only one of those, and they feel scared that they might just get kicked out. So they feel like they just have to switch because they only failed one of those, and the ultimatum is you have to pass it now, or you're getting kicked out.

The choice of language in describing the first year experience in this case is striking as an 'ultimatum' speaks to the magnitude of the decision of becoming an engineer or not. This decision is based on their perceived academic performance in the engineering science courses. Students consistently described the first year course sequence as a "trial" period to see if they can make it. Even performing poorly in one course creates feelings of self-doubt about remaining in the major. These early experiences matter, as the decision to leave STEM usually comes after an early failure signals the student that they are underprepared, which can escalate into a "downward spiral" of confirming events unless countered by affirming messages [26]. The School's academic policy requires students to retake a failed course in the subsequent semester or face consequences of dismissal. One failed course places a student on a retention list and two consecutive semesters with a failed course leads to a dismissal letter from the School, although there is an appeal process. This policy is explained to students during the first year professional seminar and can create anxiety for some students. The first year student continues to describe how the ultimatum:

will really scare engineers, at least here, out of engineering because they feel that 'The entire course curriculum is like this. If I fail anything I have to get out'... I have a friend who actually left engineering because he did not enjoy doing the courses,... He was too stressed, so he just switched to another major, he felt it was easier to just move on to something else.

This quote points out an important interpretive mismatch between the program and the students. Where the program sees the two chances with right of appeal as a flexible policy responsive to student circumstances, students, especially those with less experience with college, see this as pressure to never make a mistake. Such pressure to perform can in fact depress student performance on assessments.

Students receive mixed messages from their peers inside and outside engineering about staying in the program. Students from outside the major often express a combination of sympathy and respect for engineering students, based on the perception that their majors are very difficult. $A$ couple of examples demonstrate what engineering students hear from their peers outside of engineering: 
"Other students? Um. Yeah. That's for sure. They definitely, you know say, oh she's an engineering major. She has to study a lot so, you know, she can't hang out with us too much."

S- Whenever I mention my major, people always go, ...tell me that they're sorry.

I- And this is people you mean other students or faculty or...

S- No, they're students. So, I feel like they're...they're...I feel like they kind of feel bad for me, almost?

I- Oh, that's funny.

$S$ - Because, uh, it's been like known to be a really difficult major.

For students on the fence about remaining in the major, these comments have double messages and come at a time when values in one's personal identity are still being developed. On one hand there seems to be a tremendous amount of respect for being in what is perceived as the most challenging program on campus. At the same time, there is an implication that you are giving up on the broader college social life. This dynamic plays out within the engineering cohort as well. For example, a FY Asian American female student switched out of an engineering major during her first year and her friends who remained in the major expressed sarcasm about her decision to leave.

"why'd you leave. You know, now you're part of the statistic and we're like, alright. Whatever. We're gonna ignore you." Um. Besides that, some people have said, "oh now you have an easier workload. Stop complaining."

The loss of respect for students who leave engineering by their peers in the major may be exacerbated for those coming from underrepresented groups, like women and students of color. Not "becoming a statistic" is a common rallying point for combating stereotype threat, but can have diminishing returns - and a higher emotional cost - over time [27]. Another student described how there is a disparity between males and females in her courses and she has noticed more women than men considering switching out of the major.

It's just even in my classes, um, when I talk to people in their engineering majors, it's like I know more males than females and some of the females I know currently are, like, thinking of switching their major already.

This has been observed elsewhere, while women have higher retention rates after the first year, during the first year women tend to leave engineering at higher rates than men [28]. However, the perception that women and students of color leave engineering more often may 
seem even higher, because it both confirms stereotypes and because these groups already have lower numbers.

The juniors in the program also reflected on their first year experience as difficult but at the same time described it as a necessary step one has to overcome. Stevens et al describes navigation through important milestones as one dimension of becoming an engineer [10]. In this case, passing the first year courses is the milestone that prepared them for their

engineering content courses. Two female students describe their experiences with first year courses.

You also, you have to take the basic classes. You can't go through the engineering class without knowing physics and chem. You have to go through it. You just have to do it. I don't think they can change it. They just have to get through it...I'm glad I stuck to it because after freshman year, I wasn't sure, but once we got into those specific classes and we really learned more about civil engineering as opposed to just science. That's when I confirmed that yes, I want to keep doing this.

In this first example, passing the first year courses validated this student's decision to stay in the major and contributed to her self-identification as an engineer. However, while "get[ting] through" the first year courses confirms students' confidence in their academic ability, the later discipline-specific courses confirm self-identification as engineers "as opposed to just science". Students struggling with the first year curriculum may, as in the example below, experience more of a disconnect between their first year courses ("those courses") and the real training in engineering ("my engineering classes"). At the same time, the student recognizes the first year courses made her a better student and prepared her for her engineering courses.

I think I was pretty frustrated because things like physics and calculus I wasn't doing as well as I wanted to be. I was putting in the work and I feel like those classes prepared me to be more of a student, like a better student, when I did get to my engineering classes. I can definitely understand. I was really frustrated not getting to engineering as fast as I could. If I had taken one of the classes I'm taking now, a little bit earlier, I might have been more interested. I didn't even know. I did look for an internship this summer but I didn't know anything about engineering itself.

\section{Professional courses}

The professional non-credit seminars during the first year present a second measure students use to calibrate how well they feel they "belong" in engineering. During the professional seminar courses students are introduced to the various engineering disciplines, they attend seminars by professional engineers, and have discussions about ethics and societal impacts. 
Some of these discussions can be interpreted differently by students and used to formulate a decision about continuing in engineering. One FY student realized the impact of her future career as the class discussed how a mistake in the design of a device or a structure can have severe consequences for people and society.

I would not want to be responsible for the death of someone because of my ignorance. Um. But, in, like, reversely, it kind of made me more passionate about it 'coz I 'wanna make sure that, you know, if I was there and if I get the right training and everything, that won't happen.

In another sense, it can seem there is no room for error in the profession, as one student describes the ethics of giving students partial credit when they don't get the correct solution. A FY African American student explained there should be no partial credit in engineering courses because if a bridge collapses due to incorrect calculations, then as an engineer, "you could, like, put other's lives in danger. Like, just by like, the smallest mistake. So... I just think, like as a, like being a very cautious of what you're doing." This response is likely related to an ethics case study in which first year students study the deadly Kansas City Hyatt skywalk collapse caused in part by a redesign that was never properly analyzed by an engineer. A portion of the dialogue includes a discussion/debate among the students regarding whether professors should award partial credit for answers that are not fully correct. One intended take-home message from this debate is that critical calculations and designs should undergo quality control and safety reviews by more than just a single engineer.

Taken together with the sense that passing the first year courses is an "ultimatum", these factors reflect a powerful belief among first year students that the profession (and program) makes little room for error.

\section{Program Climate from Junior/Senior Year (JSY) Student Interviews}

Where the first year students focused primarily on academic survival as key to developing a belief they belong in engineering, more senior students had a broader view of their program environment and engineering culture. Most undergraduate engineering programs in the United States are dominated by white, middle class, straight male students (and faculty) so they are the main contributors to the social dynamic of the school's climate. Those that are part of the dominant culture are better prepared to navigate through the social spaces and sometimes do not see the inequalities present [24]. For example, one JSY white male student described his classmates in the engineering program: 
it is pretty diverse actually. I guess I was pretty surprised about ... There's some kids that are your stereotypical, all they do is study. There's some kids that all they do is party, somehow still get good grades... There's some Spanish kids, white kids, athletes, non-athletes, it's a whole big group of people.

By diversity, this student deliberately equates racial and ethnic characteristics with affinity groups and other individual characteristics. This conflation of ascribed and achieved statuses is typical of what Bonilla-Silva refers to as "colorblindness" in which racial and ethnic statuses are reduced to individual attributes rather than recognized as a means through which individuals navigate structured inequality [22]. For example, the only stereotype this student calls out is that engineering students study all the time.

Among other things, colorblindness allows white students to perceive that historical disadvantage and under-representation might actually result in "reverse discrimination" in fields like engineering. For example, a JSY biomedical engineering student, describes how he believes he could face discrimination because of his race when going through his job search.

White males are actually 'discriminated' against in engineering ... because there's so many of us that they want to get the diversity and bring females in engineering, bring different races, get some of the different ethnicities in engineering. So that kind of puts white male[s] at a disadvantage because there's already so many of them out there.

This belief is in contrast to what some of the marginalized students perceive about their classes. For example, a white JSY male student who identifies as gay commented that in his major, "it's mainly just white men. Sometimes we have minorities but there's not a lot of black people. Not a lot of Hispanic people." He goes on to say that he feels outside of his social engineering group even though he has one of the highest GPAs in his major.

I feel like I don't fit in with the people in my major. I've gotten to the point where I don't care. I wanted to be friends with them at first but ... I don't want to generalize them because there are a lot of people in my major that I do really like and they're great people and I like studying with them. There are also a lot that I just don't particularly care for. It's weird.

If a student is not able to socially integrate into the dominant culture then there is usually another informal experience that allows them to persist. Some of these include exhibiting a strong academic performance, completing an internship, participating in a research project with a faculty member, or taking a leadership role in a professional student chapter. These other informal experiences can facilitate navigation through the social spaces and help to validate 
their engineering identity. However, students from the majority group view these as a result of personal and individual preferences, not related to climate or structured disadvantage.

Individual achievement and merit are at the heart of how students of color interpret their own success in the program. A JSY male vice-president of a student organization describes how an extracurricular experience reinforced his identity as an engineer and his self-efficacy in his engineering habits of mind. He envisions himself succeeding in industry after graduation,

so, my Sophomore year, I participated in the Mayo Business Competition, and my team went far enough to get second place. That experience, in itself, was what ... I was like, "Should I have majored in Business?" Here's an engineer in a business competition, selling this fake product, and I'm like, "This is it. I'm good at that." I realized I could do it, and I could've done it if I wanted to, and probably excelled at it, ... I've heard people tell me time and time again, "Oh my God. You're an engineer. That's cool because you really know how to communicate. You really talk to people." I'm like, "Yeah, that's just the type of engineer I want to be." So, yeah. I mean, a lot of engineers are like that, too, this day and age. It's not just me. I realized that soon enough. I'm using that as a strength. I'm using it to my advantage, as an advantage.

These informal experiences are valuable to students as they validate their engineering identity. Carlone and Johnson, in their work with women scientists of color, point out that persistence in science for underrepresented groups often entails defining for oneself what being a scientist means [29]. In this account not only did his accomplishments help the team perform well in the competition, but also other people were impressed with his ability to "talk to people" as an engineer. It is clear that his confidence in being an engineer grew after this competition, but also his affiliation with "the type of engineer I want to be". In addition, his academic performance in his courses reinforce his preparedness for an engineering career. He goes on to talk about the job search process and preparing for interviews:

For me, I put myself in a lot of leadership positions while I was at [the institution], and I think that prepared me. So, indirectly, it did in terms of allowing me to take on these roles, and allowing me take on these opportunities. It has prepared me to be able to constantly go in there and show them who I am ... I feel so confident going in because I actually know my stuff, and I go in, even though it's not directly related to things that I did in class, but the confidence of being analytical and being able to answer questions and solve problems, I think that ... I feel very confident going in. You give me a problem to solve and I'll solve it because I've been doing that for four years at [the institution]. 


\section{Professional Engineering Identity for Female Juniors}

Many of the JSY white female students expressed in their interviews never experiencing overt discrimination and genuinely considered everyone was treated equally in the program. We suggest that like colorblindness, these students may be engaging in a gender-blind narrative that emphasizes individual merit over structural disadvantages. The curricular structure, where only those who 'survive' the rigorous first year courses can access the "real" engineering classes, reinforces the sense of academic meritocracy. This logic fits with the empirical reality that women - particularly white and Asian women - tend to have higher classroom performance than men.

Irrespective of their academic ability, some women described having their engineering skills invalidated by male students or their belonging in the profession mocked by professors. In one example, a white male JSY student described a situation in the classroom where he thought a professor was treating women differently.

"there was one professor, that I'm not going to say a name, anyway ... everyone who's an engineer knows who he is. They all know that he's ... He means well but he comes across as pretty sexist ... At one point, he told one of the girls that she should just marry a nice guy (laughs)."

A female JSY student discussed how she was treated differently in a circuits lab by her male friend who did not want her to touch the circuit. This reflects overall cultural tropes that although women may have stronger academics, men are associated with the hands on practices of engineering - such as tinkering with equipment.

"it's kind of gross actually. The worst I think for me was that circuits lab. That my good guy friend felt weird about me using the equipment because he thought I was going to do it wrong ... He'd be like, "I got it," in the way that guys just brush it off and act like they're more manly or whatever. I ended up doing way better in the class than he did, so I clearly could have helped, but whatever. It's just very frustrating"

Another female JSY student didn't believe she was treated differently by other students because she was a woman, but because she was a woman in a sorority. She recollects how male friends in her homework group would check answers with each other but would not ask her for her answers. Even professors would treat her differently.

I don't know if I want to say this but that I'm a girl in a sorority. That kind of adds something. People think I'm not as smart because of that ... Sometimes I wear letters, like my sorority letters, and you do get looks, you do get judged. Sometimes, I don't know, if I were to wear letters and answer a question wrong, they're just like, "Oh, she's just a dumb sorority girl, I 
don't blame her for not knowing." You can just see it on their faces, and it's kind of frustrating. Then if a guy gets an answer wrong, they'll talk it with them, try to get to the right answer. This isn't all professors, this is just a few.

Students also projected concerns about differential treatment by gender into their future employment. When probed about how they might be treated when they enter the engineering workforce because of their gender, two female students acknowledged that the engineering workplace is male dominated, there is a wage gap, and sometimes one has to adopt "professional" - stereotypically male - characteristics to fit in.

I have been told that I have to have a firm handshake because in the professional world, meeting a female engineer people are a little judgmental. Men can be, just assume less just because you're a woman engineer. Got to get that handshake firm.

There's less women, I don't know if that's going to help me. Then, there's also the wage gap thing, which makes me angry. It makes me nervous.

These gendered experiences fit with recent work focused on informal learning experiences, such as internships and within teams, as the site where traditional gender stereotypes operate. As students move into the upper level curriculum, and away from courses relying on sheer academic ability, these experiences may send different messages about belonging to students from different groups.

\section{Student perceptions regarding differential treatment}

To add to the qualitative interpretation of the interviews, quantitative data from a pilot survey [16] is presented to demonstrate junior student experiences are widespread. In particular, the index of differential treatment shows that more than one in five $(20.7 \%)$ juniors reported they had been discriminated against based on gender as a student in engineering; this proportion was higher for women (35.0\%) than for men (13.2\%) and was statistically significant (Chi square $=16.094, p=0.001)$. Nearly one in four (24.6\%) responded they either "somewhat agreed" or "agreed" to being made aware of their gender as a student in engineering; this proportion rose to more than half $(55.0 \%$ ) of women, compared with only $8.1 \%$ of men (Chi square $17.180, p=$ .001). These data suggest that women and men in engineering do have gendered experiences as engineering students, although they curiously do not attribute this situation to either the faculty and staff or the other students in the engineering program. Only $8.6 \%$ of the juniors surveyed suggested that the faculty and staff treat students differently on the basis of gender, and only $6.9 \%$ indicated that other engineering students did (neither of these statistics showed statistically significant differences between men and women students). 
Similarly, more than a quarter $(26.7 \%)$ of students who self-identified as non-white and/or Hispanic (i.e., racial and ethnic minorities) indicated they had experienced discrimination based on their race or ethnicity as an engineering student (compared with only $2.3 \%$ of white, nonHispanic students, Chi square $=17.619, p=.001)$. More than half of minority students $(53.3 \%)$ said they were "often made aware" of their race or ethnicity as an engineering student, while only $9.3 \%$ of white non-Hispanics did (Chi square 19.922, p. $=.001$ ). As with gendered experiences, only $10.4 \%$ of students suggested faculty and staff treated students differently on the basis of race or ethnicity and only $6.9 \%$ said other engineering students treated them differently, with no statistically significant difference between minority and white, non-Hispanic students.

These numbers are particularly interesting given that first-year students who were surveyed reported almost no experiences of gender or racial/ethnic discrimination $(2.2 \%$ of each, with no statistical differences between groups) or little unequal treatment by faculty and staff or other students (although one woman and two minority respondents did report differential treatment).

\section{DISCUSSION:}

From the first year student interviews, it is clear there exists a make or break climate in the engineering program where there is very little room for error. Students form ideas of "being" and "becoming" an engineer from their course performance, peer interactions and professional seminars. Those who recognized similarities in content to what they studied in high school expressed a relative comfort in the first year courses. The idea of switching majors was contemplated by many of the female and underrepresented students especially if the academic load seemed difficult. The fact that at least one student described the academic rigour of the first year experience as an 'ultimatum' speaks perhaps to the strict policies of the engineering program. The School's academic dismissal policy reinforces a meritocratic system as students who are not performing well are dismissed. This type of policy favors majority students who come to an institution with more accrued advantages [24]. It discounts those with emerging technical skills who might otherwise bring funds of knowledge, leadership, communication, and management skills. Moreover, being dismissed from the School carries a large emotional burden as it effectively denies a student's engineering identity and forces them to reformulate their career path $[10,15,30]$. It should be mentioned that many institutions have strict policies in place to ensure that students who underperform can leave engineering earlier and have more academic alternatives. Prolonging an engineering student's time-to graduation can inevitably lead to low job prospects [31]. Strict policies can be of benefit for larger research 
institutions and perhaps for smaller institutions with fewer resources. Meyer and Marx recommended introductory courses address the realities of the engineering profession and the commitment to the major in order to have transitioning students save time, money and emotional turmoil [15]. In the end, it is up to the engineering program to determine what policy serves them best.

Developing the sense of belonging within the program is complex as the first year experience is an individualistic process in a new environment where peer interactions can have a tremendous influence on the decision to remain in the major. Stevens et al describes how identity formation is a double-sided phenomenon which involves the way one sees themselves as an engineer and how others position that person as an engineer [9]. If a peer recognizes a student as possessing engineering habits of mind, such as communication, creativity, or problem solving ability, then it reinforces the student's confidence in pursuing their professional aspirations. Conversely if an engineering student expresses doubts to others about remaining in the major then their peers will likely support the individual's belief of exploring another major.

Solidarity within the engineering major eventually occurs but it takes time to foster those relationships and friendships. Although the juniors and seniors did recall the difficulty and frustration of their first year they still believe it to be a necessary gatekeeper of access the engineering courses. By surpassing the first year milestone, they can identify as engineers in training. By the junior year, students have taken courses together and have collaborated on many team projects. They study together and they participate in social gatherings with engineering friends. The formation of solidarity [9] is evident in the junior year within each specific major. A civil engineering JSY student describes the social integration in her class:

I feel like we're really like a team. You know what I mean? There's 18 of us, and we all know each other really well and if I ever have any problems with anything, I can go to all other 17 students and they will help me, or try to help me. I feel like we're not really that competitive. We just all want each other to graduate.

There is evidence from the transcripts that every participant from civil engineering felt this way about the social integration of the group. Whether white male, female or student of color they all felt like they belonged in the group. At least three students from different racial groups specifically mentioned being integrated socially and it's important to note they all had internship experiences by this point and were active in different student organizations. Not only do they exhibit social integration but they also show from their varied experiences a professional integration into engineering. 
From the interview transcripts and the survey responses, it is reasonable to suggest there are gendered and racialized experiences for undergraduates, and that these are perceived more by women and students of color. However, engineering students are unwilling to name the source of these differential experiences, which is consistent with an internalized belief that people are being treated equally and based on characteristics other than gender or race/ethnicity even when the students themselves report differential and sometimes discriminatory experiences. Bonilla-Silva explains how students can believe both can be true by noting that the system of unequal treatment is generally perceived to be neutral and meritocratic-even though there are clearly unequal experiences. It is this situation with regards to race that Bonilla-Silva describes as "colorblind" or "racism without racists" - an environment that lacks racist individuals and overtly racist actions but nonetheless produces different racial outcomes [22]. In other words, this describes structural and cultural racism, rather than individual discriminatory beliefs or actions. Unfortunately, these sorts of systems are much more difficult to fix, as they are subtle and internalized, rather than overt and obvious. At the same time, the persistent underrepresentation of some groups in undergraduate engineering continues to indicate that something makes the experience less hospitable for historically underrepresented groups-even though this something is not perceived by the students to come from the people they interact with as students.

This meritocratic understanding also manifests in what McLoughlin (2005) called "spotlighting," whereby historically underrepresented groups-- and particularly women in engineering-- are made to feel different in order to "help" them [31]. In the interviews, both male and female respondents reported that they had been told formally or informally that because of the historical underrepresentation in women in engineering, that they would have a competitive advantage in the job market. Unlike situations of overt discrimination and tacit, chilly climates, this type of spotlighting may reinforce insecurities among the spotlighted group and resentment among others.

\section{CONCLUSION:}

By taking a qualitative look at engineering climate in the first year we can see there are two formal measures that students utilize to decide if they want to remain in their major: 1) The perception of an "ultimatum" tied to academic performance during the first year course load, and 2) the lessons learned in professional courses. We suggest these foci on professional performance allows students to view their learning environment as fundamentally meritocratic and thus, they are able deemphasize everything except individual performance for explaining success in the engineering program and the profession as a whole. Because of their sense of accomplishment and solidarity within their programs, students are hesitant to cite 
discrimination and structural barriers, but focus instead on their own success and fit as students. The problem with this strategy, however, is that by implication, it suggests that because of individual skills, interests, and dedication, engineering is simply not a good match for individual students, and thus the persistent underrepresentation of women and students of color is a reflection of personal characteristics and preferences. We found this even though many of our junior respondents and our differential treatment index survey results suggest that the experiences of engineering students varied by gender, race, and ethnicity.

\section{ACKNOWLEDGMENTS:}

This research was funded by the National Science Foundation, NSF Award \#1544192. The authors are grateful for the research students who transcribed the interviews and also the students from the Fall 2016 Sociology 390 faculty-led research course who performed some of the data collection and analysis, especially Alexandra Aneiros, Nicole Athan, McKenzie Black, Dacontee Davis, Andrea Elfers, Gabriela Garcia, Kathleen Mclltraith, Megan Synek and Jennifer Teets.

\section{REFERENCES:}

[1] National Science Board, "Preparing the Next Generation of STEM Innovators: Identifying and Developing our Nation's Human Capital." 2010.

[2] L.L. Long III and J.A. Mejia, "Conversations about diversity: Institutional barriers for underrepresented engineering students," J Eng Educ, vol. 105, pp. 211-218, 2016.

[3] J. Walther, N. Kellam, N. Sochacka and D. Radcliffe, "Engineering competence? An interpretive investigation of engineering students' professional formation," J Eng Educ, vol. 100, pp. 703-740, 2011. [4] ABET Engineering Accreditation Commission, "Criteria for Accrediting Engineering Programs," ABET., 2018.

[5] R.H. Todd and S.P. Magleby, "Elements of a successful capstone course considering the needs of stakeholders," European Journal of Engineering Education, vol. 30, pp. 203-214, 2005.

[6] C. Gewirtz, D.A. Kotys-Schwartz, D. Knight, M. Paretti, S. Arunkumar, J.D. Ford, S. Howe, L.M. Rosenbauer, N.E. Alvarez and J. Deters, "New Engineers' First Three Months: A Study of the Transition 
from Capstone Design Courses to Workplaces," in Proceedings of the ASEE Annual Conference \& Exhibition, 2018.

[7] A.J. Dutson, R.H. Todd, S.P. Magleby and C.D. Sorensen, "A review of literature on teaching engineering design through project-oriented capstone courses," J Eng Educ, vol. 86, pp. 17-28, 1997. [8] B. Sepahpour, "Serendipitous Advantages of a Multidisciplinary Senior Seminar Course for Engineering Students," in Proceedings of the ASEE Annual Conference \& Exhibition; Exposition, Seattle, Washington, 2015.

[9] C.L. Dym, A.M. Agogino, O. Eris, D.D. Frey and L.J. Leifer, "Engineering design thinking, teaching, and learning," J Eng Educ, vol. 94, pp. 103-120, 2005.

[10] R. Stevens, K. O'connor, L. Garrison, A. Jocuns and D.M. Amos, "Becoming an engineer: Toward a three dimensional view of engineering learning," J Eng Educ, vol. 97, pp. 355-368, 2008.

[11] M. Hoit and M. Ohland, "The impact of a discipline-based introduction to engineering course on improving retention," J Eng Educ, vol. 87, pp. 79-85, 1998.

[12] D.W. Knight, L.E. Carlson and J.F. Sullivan, "Improving engineering student retention through handson, team based, first-year design projects," in Proceedings of the International Conference on Research in Engineering Education, 2007.

[13] National Center for Science and Engineering Statistics, "Women, Minorities, and Persons with Disabilities in Science and Engineering: 2017 Special Report NSF 17-310." 2017.

[14] J.R. Duncan and Y. Zeng, "Women: Support Factors and Persistence in Engineering. Research in Engineering and Technology Education." National Center for Engineering and Technology Education, 2005.

[15] M. Meyer and S. Marx, "Engineering dropouts: A qualitative examination of why undergraduates leave engineering," J Eng Educ, vol. 103, pp. 525-548, 2014.

[16] B. Sepahpour, P.E. Steven Schreiner, D.C. Bates, S. Kim and J.L. Gazley, "Board\# 134: Creating an 
Instrument to Assess the Professional Formation of Engineering Students at The College of New Jersey (TCNJ)," in Proceedings of the ASEE Annual Conference \& Exposition, 2017.

[17] N. Dasgupta, "Ingroup experts and peers as social vaccines who inoculate the self-concept: The stereotype inoculation model," Psychological Inquiry, vol. 22, pp. 231-246, 2011.

[18] M. Estrada, A. Woodcock, P.R. Hernandez and P.W. Schultz, "Toward a model of social influence that explains minority student integration into the scientific community." J. Educ. Psychol., vol. 103, pp. 206, 2011.

[19] J.L. Gazley, R. Remich, M.E. Naffziger-Hirsch, J. Keller, P.B. Campbell and R. McGee, "Beyond preparation: Identity, cultural capital, and readiness for graduate school in the biomedical sciences," Journal of Research in Science Teaching, vol. 51, pp. 1021-1048, 2014.

[20] E. Tan, A. Calabrese Barton, H. Kang and T. O'Neill, "Desiring a career in STEM-related fields: How middle school girls articulate and negotiate identities-in-practice in science," Journal of Research in Science Teaching, vol. 50, pp. 1143-1179, 2013.

[21] D. Holland, W. Lachicotte, D. Skinner and C. Cain, "Identity and agency in cultural worlds," Cambridge, MA: Harvard, 1998.

[22] E. Bonilla-Silva, Racism without racists: Color-blind racism and the persistence of racial inequality in America, Rowman \& Littlefield, 2017.

[23] C. Seron, S.S. Silbey, E. Cech and B. Rubineau, "Persistence is cultural: Professional socialization and the reproduction of sex segregation," Work Occup., vol. 43, pp. 178-214, 2016.

[24] C.E. Foor, S.E. Walden and D.A. Trytten, "“I wish that I belonged more in this whole engineering group:" Achieving individual diversity," J Eng Educ, vol. 96, pp. 103-115, 2007.

[25] A. Trauth, T.N. Barnes, J. Buckley, J.A. Enszer, S.I. Rooney and R. Davidson, "How Granular is the Problem? A Discipline-specific Focus Group Study of Factors Affecting Underrepresentation in Engineering Undergraduate Programs," in Proceedings of the ASEE Annual Conference \& Exposition, 
2018.

[26] E. Seymour and N.M. Hewitt, "Talking about leaving: Why undergraduates leave the sciences," Boulder, CO: Westview, 1997.

[27] E.O. McGee and D.B. Martin, "“You would not believe what I have to go through to prove my intellectual value!" Stereotype management among academically successful Black mathematics and engineering students," American Educational Research Journal, vol. 48, pp. 1347-1389, 2011.

[28] M.J. Borrego, M.A. Padilla, G. Zhang, M.W. Ohland and T.J. Anderson, "Graduation rates, gradepoint average, and changes of major of female and minority students entering engineering," in Frontiers in Education, 2005. FIE'05. Proceedings 35th Annual Conference, pp. 1, 2005.

[29] H.B. Carlone and A. Johnson, "Understanding the science experiences of successful women of color: Science identity as an analytic lens," Journal of Research in Science Teaching, vol. 44, pp. 1187-1218, 2007.

[30] V. Tinto, "Through the eyes of students," Journal of College Student Retention: Research, Theory \& Practice, vol. 19, pp. 254-269, 2017.

[31] M.W. Ohland, C.E. Brawner, M.M. Camacho, R.A. Layton, R.A. Long, S.M. Lord and M.H. Wasburn, "Race, gender, and measures of success in engineering education," J Eng Educ, vol. 100, pp. 225-252, 2011. 